\title{
MERUNUT LEADERSHIP CHARACTERS RAJA-RAJA JAWA BERDASARKAN MANUSKRIP KLASIK
}

\author{
Endang Nurhayati, Hesti Mulyani, dan Venny Indria Ekowati \\ Universitas Negeri Yogyakarta \\ endang_nurhayati@uny.ac.id, hesti mulyani@uny.ac.id, dan venny@uny.ac.id
}

\begin{abstract}
ABSTRAK
Penelitian yang berjudul Merunut Leadership Characters Raja-Raja Jawa Berdasarkan Manuskrip Klasik dan Implementasinya pada Kepemimpinan Masa Kini ini bertujuan untuk: mendeskripsikan nilai-nilai kepemimpinan para raja Jawa yang terkandung dalam manuskrip Jawa. Penelitian ini menggunakan metode penelitian kepustakaan dengan sumber data berupa manuskrip klasik Jawa yang berjudul Serat Wedhatama dan Serat Wulangreh. Berdasarkan hasil pembahasan, Analisis dilakukan dengan menggunakan teknik analisis kualitatif. Berdasarkan hasil pembahasan, didapatkan simpulan bahwa leadership characters yang paling ditekankan dalam dua karya sastra karangan raja-raja Jawa ini berturut-turut adalah: rendah hati, waspada, sabar, taat beragama, prihatin, suka bekerja keras, mampu mengintrospeksi diri, berpendirian teguh, menjunjung tinggi nilai kesusilaan, tekun, santun, dan lain-lain.

Kata kunci: karakter kepemimpinan, raja, Jawa, manuskrip
\end{abstract}

\begin{abstract}
The research entitled Leadership Characters of Java Kings Based on Classical Manuscripts and Its Implementation on Today's Leadership aims to: describe the values of the leadership of the Javanese kings contained in the Javanese manuscripts. This research uses literature research method with data source in the form of Javanese classical manuscript entitled Serat Wedhatama and Serat Wulangreh. Based on the results of the discussion, the analysis is done by using qualitative analysis techniques. Based on the results of the discussion, it is found that the most emphasized leadership characters in these two works of literary essay of Javanese kings are: humble, alert, patient, devout, concerned, hardworking, able to introspect, uphold the value of decency, diligence, courteous, and others.
\end{abstract}

Keywords: leadership characters, kings in java, manuscript

\section{PENDAHULUAN}

Sekelompok masyarakat tutur yang mapan peradabannya, selalu memiliki seperangkat aturan yang mapan dan diikuti masyarakatnya. Aturan tersebut berlaku secara turun temurun seiring dengan perjalannya waktu pemakainya. Dalam kurun waktu tertentu seperangkat aturan akan tergilas waktu jika tidak sempat didokumentasikan. Tradisi mendokumentasikan aturan-aturan perikehidupan sekelompok masyarakat tutur dilakukan dengan maksud untuk memberikan peninggalan warisan budaya kepada generasi berikutnya, agar tetap beradab.Teknik pendokumentasian ikhwal kebudayaan lazim dilakukan dengan 
cara ditulis. Hasil tulisan ini disebut naskah atau manuskrip. Baroroh Baried (1985) menjelaskan manuskrip adalah bahan tulisan tangan yang menyimpan berbagai pemikiran dan perasaan sebagai hasil peradaban masa lampau. Marsono (2010) menjelaskan bahwa manuskrip di Indonesia sangat banyak jumlahnya, sampai sekarang belum terhitung secara pasti. Manuskrip-manuskrip ini menanti untuk disentuh kemudian dibuka dan dicermati isinya, dan hasilnya untuk dimanfaatkan .

Menurut Loir dan Faturahman (1999), masyarakat Jawa memiliki tradisi tulis yang sangat produktif. Pernyataan tersebut dapat dibuktikan dengan bukti jumlah manuskrip yang tersimpan diberbagai perpustakaan seperti Sonobudaya menyimpan 1255 (Behrend, 1990), Pura Pakualaman sebanyak 251 (Saktimulya, 2005), kraton Yogyakarta sebanyak 750 manuskrip (Marsono, 2007).Manuskrip klasik Jawa ditulis sejak masa pra Islam sampai dengan abad ke-19 (Pigeaud,1967:1).Manuskrip-manuskrip Jawa merupakan saksi sejarah peradaban bangsa Jawa dari masa peradaban Jawa kuna sampai kini. Manuskrip-manuskrip tersebut memuat berbagai bukti bahwa bangsa Jawa memiliki peradaban yang sangat maju, di bidang agama, norma/etika, tatanan sosial, budaya, politik, tata hukum, tata negara, ekonomi, arsitektur dan lain sebagainya (Sunyoto, 2012:31). Salah satu wujud peradaban Jawa tersebut yang patut dikaji, dipahami isinya dan diamalkan dalam kehidupan adalah pola kepemimpinan para tokoh-tokoh Jawa masa lampau atau tata negara.

Sultan Agung misalnya, beliau adalah salah satu leluhur para raja Mataram Baru yang memiliki jiwa patriotisme yang tinggi. Sultan Agung bersama rakyatnya berjuang melawan penjajah, dalam rangka memerdekakan negerinya dari cengkeraman penjajah. Dengan sifat berbudi bawaleksana beliau mampu menggerakkan rakyatnya bersama-sama mengusir kumpeni. Sebagai seorang raja beliau juga mendokumentasikan peradaban pada masanya dalam karyanya yang tersohor yaitu Satra Gendhing.

Tokoh lain yang memiliki jiwa kepempinan laiknya wakil Tuhan adalah Sultan Hamengku Buwana V, Sunan Paku Buwana IV, KGPA Mangkunegara IV, dan lain-lainnya, mereka masing -masing pun mendokumentasikan gaya kepemimpinan mereka dalam karya sastra. Nilai-nilai kepemimpinan yang layak diteladani, dan dicoba diterapkan kembali di masa yang bebas dan demokrasi yang melentur ini dapat digali lewat karya-karya mereka.

Dalam Serat Jatipusaka Hamakutharaja Sultan Hamengku BuwanaV mencoba mendokumentasikan gaya kepemimpinan raja yang mampu membangun negerinya menjadi ayom-ayem, dengan langkah mampu memahami asal-usul dumadi, memperkuat keberadaan dinastinya, paham aturan memimpin, bersikap adil, berhati suci dan lain-lainnya (Nurhayati, 2006:54-55). KGPA Mangkunegara IV mendokumentasikan pola kepemimpinan dalam Serat Tripama. Pemimpin yang perlu dicontoh adalah pemimpin yang memiliki watak dan sikap seperti setya atau tidak ingkar, patriotik, dan mau berkorban. Sifat pemimpin yang baik digambarkan dalam tiga tokoh legendaris yaitu Kumbakarna, Suwanda dan Karna.

Berbeda dengan tokoh-tokoh yang telah disebut Sunan Paku Buwana IV mendokumentasikan pola kepemimpinan yang baik dalam Serat Wulang Reh. Pemimpin harus aktif belajar, paham ilmu agama, mampu bergaul dengan tepat. 
Hal ini termuat dalam kutipan berikut:padha gulangen ing kalbu, ing sasmita amrih lantip, aja pijer mangan nendra, kaprawiran den kaesthi, ..(pupuh 2, kinanthi) 'tanamkan/ajarkan di hatimu, agar persaanmu cerdas, jangan terlena dengan makan dan tidur, upayakan selalu menang/unggul..'

Untuk memahami secara rinci nilai-nilai kepemimpinan yang termuat dalam manuskrip klasik Jawa tersebut, pada kesempatan ini akan dikaji pola-pola kepemimpinan raja-raja Jawa (Mataram), nilai-nilai ajarannya, relevansinya nilainilai kepemimpinan masa lampau dengan kepemimpinan masa kini serta merumuskan watak dan sikap pemimpin yang mampu memayu hayuning bawana, dengan jiwa ing ngarsa sung tuladha, ing madya mangun karsa, dan tut wuri handayani (Darmoko, 2012:8).

Kajian terhadap pola-pola kepemimpinan Jawa tersebut akan menghasilkan deskripsi kepemimpinan berdasarkan cara dan karakter kepemimpinan raja-raja Jawa. Deskripsi dan pola ini kemudian akan menghasilkan model-model kepemimpinan yang mampu bertahan dalam berbagai perubahan peradaban.

\section{METODE PENELITIAN}

Penelitian ini menggunakan metode penelitian. Penelitian pustaka bersifat ready made atau siap pakai. Artinya peneliti tidak melakukan penelitian lain, kecuali berhadapan dengan teks dan bahan sumber yang berupa pustaka-pustaka. Data penelitian dilakukan dengan teknik purposive sampling. Data ditetapkan dengan karakteristik tertentu. Jadi teks-teks dalam manuskrip Jawa yang dipilih adalah yang memuat mengenai ajaran kepemimpinan raja-raja Jawa. Data primer berupa artefak budaya dalam bentuk tertulis yaitu manuskrip-manuskrip Jawa yang ditulis sekitar abad 17 dan $18 \mathrm{M}$. Data sekender diambil dari jurnal ilmiah, internet, buku-buku literatur, arsip, dokumen resmi, dokumen pribadi, dan teksteks manuskrip yang dapat dipakai sebagai pendukung data primer. Berdasarkan pembacaan pada naskah-naskah Jawa, diputuskan mengambil teks Serat Wulangreh dan Serat Wedhatama. Dua naskah ini diambil sebagai sumber penelitian karena memuat berbagai ajaran tentang kepemimpinan. Selain itu, Serat Wulangreh dan Wedhatama juga ditulis oleh dua orang raja besar yang mumpuni dalam bidang pemerintahan. Serat Wulangreh dikarang oleh Sri Susuhunan Pakubuwa IV, dan Serat Wedhatama dikarang oleh Mangkunegara IV.

Pengumpulan data dilakukan dengan (1) mendeskripsikan naskah yang menjadi sumber penelitian, (2) membaca dan mentransliterasi naskah secara cermat dan teliti, dengan berpedoman pada metode-metode filologi yang berlaku dalam proses transliterasi, (3) mencatat data-data yang berkaitan dengan tujuan penelitian dari hasil transliterasi. Gejala-gejala yang menarik minat dari data-data tersebut, kemudian dibedakan dan dipotong-potong menjadi unit-unit (satuansatuan) analisis yang terpisah. Penelitian ini menggunakan teknik analisis kualitatif. Teknik ini digunakan untuk menganalisis data yang bersumber pada manuskrip-manuskrip yang berwujud teks-teks tertulis. Data ini selanjutnya dianalisis dan diinterpretasikan secara luas, dalam, dan tajam. Analisis dan intepretasi data ini menggunakan teori-teori dan metode-metode filologi dan sastra. 


\section{HASIL PENELITIAN DAN PEMBAHASAN}

Berdasarkan hasil penelitian dan pembahasan, didapatkan data sejumlah $48 l$ eadership characters dalam Serat Wedhatama dan 20 leadership Characters dalam Serat Wulangreh. Berdasarkan tabulasi data mengenai leadership characters baik dalam Serat Wedhatama dan Serat Wulangreh, didapatkan simpulan bahwa leadership characters yang paling ditekankan dalam dua karya sastra karangan raja-raja Jawa ini berturut-turut adalah: rendah hati, waspada, sabar, taat beragama, prihatin, suka bekerja keras, mampu mengintrospeksi diri, berpendirian teguh, menjunjung tinggi nilai kesusilaan, tekun, santun, dan lainlain. Berikut ini diagram hasil penggabungan sifat-sifat kepemimpinan yang perlu ditekankan sebagai seorang pemimpin.

Berikut ini pembahasan lima buah sifat utama yang paling banyak disebutkan dalam Serat Wedhatama dan Wulangreh:

\section{Rendah Hati}

Karakter kepemimpinan yang paling banyak disebutkan dalam Serat Wulangreh dan Serat Wedhatama adalah rendah hati. Rendah merupakan sikap Memperhatikan kedudukan orang lain dan menghindari perilaku arogan. Kerendahan hati merupakan kualitas sifat yang mampu menarik hati manusia dan membuka kekaguman (Mahdi, 2005: 31). Selain itu tidak pamer ataupun sombong, tidak melakukan tindakan ingin dipuji, dan tidak merasa lebih dari orang lain. Merupakan definisi dari rendah hati menurut Sunarti (2005: 14).

KGPH Mangkunegara IV menyatakan dalam Serat Wedhatama, bahwa pemimpin harus memiliki sikap yang rendah hati, sebagaimana tertulis dalam kutipan dari teks data 1.3.c-d; I.3.f; I.4.f-g; I.5.c-e; I.8.e; II.22.g; II.24.g; II.31.d; III.38.e; VI.98.c- f; VI.100.c sebagai berikut.

Nggugu karsane priyangga, nora nganggo peparah lamun angling, lumuh ingaran balilu, uger guru aleman.

Nanging janma ingkang wus waspadeng semu, sinamun ing samudana, sesadon ingadu manis.

Si pengung nora nglegawa, sangsayarda denira cacariwis, ngandharandhar angendhukur, kandhane nora kaprah, saya elok alangka longkanganipun, si wasis waskitha ngalah, ngalingi marang si pingging.

Mangkono ngelmu kang nyata, sanyatane mung weh reseping ati, bungah ingaranan cubluk, sukeng tyas yen denina.

Nora kaya si punggung anggung gumrunggung, ugungan sadina dina, aja mangkono wong urip. 
Socanira jiwangganira, jer katara lamun pocapan pasthi, lumuh asor kudu unggul, semengah sesongaran, yen mengono kena ingaran katungkul, karem ing reh kaprawiran, nora iku kaki.

Pra mudha kang den karemi, manulad nelad Nabi, nayangkerat Gusti Rasul, anggung ginawe umbag, saben seba mampir masjid, ngajab-ajab mukjijad tibaning drajad.

Lamun sira paksa nulad, tuladhaning Kangjeng Nabi, o, ngger kadohan panjangkah, wateke tan betah kaki, rehne ta sira Jawi, sathithik bae wus cukup, aywa guru aleman

Mangkono janma utama, tuman tumanem sepi, ing saben rikala mangsa, masah amemasuh budi, laire anetepi, ing reh kasatriyanipun, susila anor raga, wignya met tyasing sesami, yeku aran wong barek berag agama.

Durung pecus, kesusu kaselak besus, amaknani rapal, kaya sayid weton Mesir, pendhak pendhak angendhak gunaning janma

Mangkono ingkang tinamtu, tampa nugrahaning Widhi, marma ta kulup den bisa, mbusuki ujaring janmi, pakoleh lair batinnya, iyeku budi permati

Ananging ta kudu kudu, sakadarira pribadi, aywa tinggal tutuladan, lamun tan mangkono kaki, yekti tuna ing tumitah, poma kaestokna kaki

Terjemahannya:

Hanya mengikuti kehendak diri sendiri, bila berkata tanpa perhitungan, tidak mau dianggap bodoh, hanya mabuk pujian

Namun, orang yang tahu gelagat (pandai), justru selalu merendah diri, (berpura-pura), menanggapi semuanya dengan baik.

Si Dungu tidak menyadari. Bualannya semakin menjadi-jadi, melantur tidak karuan. Bicaranya yang hebat-hebat, makin aneh dan tak masuk akal. Si Pandai maklum dan mengalah, menutupi ulah si Bodoh

Demikianlah ilmu yang sejati. Sebenarnya hanya menyenangkan hati. Suka dianggap bodoh. Gembira apabila dihina.

Tidak seperti si Dungu yang selalu sombong, ingin dipuji setiap hari. Jangan demikianlah hidup dalam pergaulan.

Sifat-sifat pribadimu, nampak apabila bertutur kata, tidak mau kalah, maunya menang sendiri, sombong dan meremehkan orang. Yang demikian dapat disebut tergila-gila akan tingkah laku kesombongan. Itu tidak terpuji nak. 
Yang digemari anak muda. Meniru-niru Nabi, Utusan Tuhan yaitu Rasul, yang hanya dipakai sombong-sombongan, setiap akan bekerja singgah dulu ke mesjid, mengharap mukjijad agar mendapat derajad (naik pangkat).

Bila kamu bertekad mencontoh. Tindak tanduk Kanjeng Nabi, oh, nak terlalu muluk namanya. Biasanya tidak mampu nak, karena kamu itu orang Jawa, sedikit saja sudah cukup. Jangan mencari pujian.

Begitulah manusia sejati. Gemar membiasakan diri berada di alam sepi, pada saat-saat tertentu, mempertajam dan membersihkan jiwa. Caranya dengan berpegang pada kedudukannya sebagai satria, bertindak baik rendah hati, pandai bergaul, pandai memikat hati orang lain, itulah yang disebut orang yang menghayati/menjalankan agama.

Belum pandai, tergesa-gesa ingin berlagak. Menerangkan rapal, seperti sayid dari Mesir. Seringkali meremehkan kepandaian orang lain.

Begitulah biasanya, mendapat anugerah Tuhan. Oleh karena itu anakku agar kau dapat pura-pura menjadi orang bodoh terhadap kata orang lain, hasilnya lahir batin, iyalah budi yang baik.

Tetapi harus ikhtiar, sekedarnya saja, jangan melupakan tauladan (contoh). Apabila tidak demikian anakku, itu berarti rugi hidup ini. Oleh karena itu jalankanlah anakku.

Berdasarkan kutipan dalam data tersebut, dapat disimpulkan bahwa KGPH Mangkunegara IV memberikan nasehat yaitu, pemimpin harus bersikap rendah hati yang tercermin dalam sikap tidak mabuk pujian belaka serta tidak menganggap dirinya paling pandai. Ia tidak boleh memiliki sikap suka meremehkan orang lain. Jika memang pandai berendah hatilah agar lebih dihormati orang lain. Sebisa mungkin berpura-puralah belum banyak mengerti demi terus belajar agar menjadi semakin pandai. Pada akhirnya ia akan memiliki budi yang baik.

\section{Waspada}

Waspada adalah orang yang mampu melihat kemungkinan terjadinya bahaya yang akan menimpanyan. Oleh karena itu, orang tersebut berhati-hati dalam tindakannya (Chodjim, 2008: 363).

KGPH Mangkunegara IV menyatakan dalam serat Wedhatama, bahwa pemimpin harus memiliki sikap waspada, sebagaimana tertulis dalam kutipan dari teks data I.3.e; IV.59.e; IV.62.d; IV.64.d; IV.67.c; IV.72.b; VI.83.b; VI.86.a- e; VI.88.b sebagai berikut.

Nanging janma ingkang wus waspadeng semu, sinamun ing samudana, sesadon ingadu manis. 
Sucine tanpa banyu, mung nyunyuda mring hardaning kalbu, pambukane tata titi ngati-ati, atetep telaten atul, tuladan marang waspaos.

Gagare ngunggar kayun, tan kayungyun mring ayuning kayun, bangsa anggit yen ginigit nora dadi, marma den awas den emut, mring pamurunging lelakon.

Sayekti luwih perlu, ingaranan pepuntoning laku, kalakuwan tumrap kang bangsaning batin, sucine lan awas emut, mring alaming lama maot.

Pametake saka luyut, sarwa sareh saliring panganyut, lamun yitna kayitnan kang miyatani, tarlen mung pribadinipun, kang katon tinonton kono.

Meloke ujar iku, yen wus ilang sumelanging kalbu, amung kandel kumandel marang ing takdir, iku den awas den emut, den memet yen arsa momot.

Mangka kanthining tumuwuh, salami mung awas eling, eling lukitaning alam, dadi wiryaning dumadi, supadi nir ing sangsaya, yeku pangreksaning urip.

Dene awas tegesipun, weruh warananing urip, miwah wisesaning tunggal, kang atunggil rina wengi, kang mukitan ing sakarsa, gumelar ngalam sakalir.

Sirnakna semanging kalbu, den waspada ing pangeksi, yeku dalaning kasidan, sinuda saka sethithik, pamothahing nafsu hawa, linalanthih mamrih titih.

Terjemahannya.

Namun, orang yang tahu gelagat (pandai), justru selalu merendah diri, (berpura-pura), menanggapi semuanya dengan baik.

Pembersihnya tanpa air. Hanya dengan mengurangi nafsu di hati. Mulai dari sikap yang baik, teliti, dan berhati-hati. Serta tetap tidak bosan dan menjadi watak. Contoh untuk waspada.

Gagalnya membiarkan kehendak, tidak tertarik kepada indahnya tujuan. Hal yang direka-reka bila dirasakan (digigit) tidak terwujud. Maka dari itu harap waspada terhadap perintang/tujuan.

Sebenarnya lebih penting. Disebut penghabisannya tindakan, tindakan yang bersangkutan dengan batin, pembersihannya dengan awas dan ingat, kepada alam lama yang maha besar (dapat memuat), alam kelanggengan. 
Sarannya dari luyut (batas lahir dan batin), serba sabar dalam mengikuti alam yang menghanyutkan. Asal waspada, dan kewaspadaan yang dapat diandalkan itu tak lain diri pribadinya yang terlihat disitu.

Kenyataan yang dibicarakan ini. Bila sudah hilang keragu-raguan hati, hanya percaya dengan sebenar-benarnya kepada takdir. Itu harap awas dan ingat. Yang cermat apabila ingin menguasai seluruhnya.

Padahal bekal/modal orang hidup, selamanya waspada dan ingat. Ingat kepada petunjuk/contoh di alam ini. Jadi kekuatan hidup, supaya lepas dari kesengsaraan, yaitu cara pemeliharaan hidup.

Artinya awas (waspada) itu, tahu penghalang kehidupan, serta kekuasaan yang satu, yang selalu bersama siang malam, yang meluluskan segala kehendak, terhampar seluruh alam.

Hilangkanlah keragu-raguan hati. Waspadalah terhadap pandanganmu. Itulah jalan yang baik, kurangilah dari sedikit, permintaan hawa nafsu latihlah agar sempurna.

Berdasarkan kutipan dalam data tersebut, dapat disimpulkan bahwa KGPH Mangkunegara IV memberikan nasihat bahwa pemimpin harus selalu bersikap waspada dalam situasi apapun terhadap siapapun juga yang ada di sekelilingnya karena akan selalu ada bahaya yang mengintai di sekitarnya.

Di samping itu, SSDISKS Pakubuwana IVmenuliskan dalam Serat Wulangreh bahwa pemimpin harus memiliki sikap waspada. Kutipan mengenai sikap waspada bagi seorang raja sebagaimana yang dimuat dalam teks data II.3.a-f , VII.4-7.a-g, dan XII.11, 15.a-i sebagai berikut.

Yen wis tinitah wong agung, aja sira nggunggung dhiri, aja leket lan wong ala, kang ala lakunireki, nora wurung ngajak-ajak, satemah anunulari.

Mapan ana sisiku telung prakara, nanging gedhe pribadi, pan iki lirira, ingkang telung prakara, aja anggunggung sireki, kalawan aja, nacad kapati-pati.

Lawan aja mamaoni barang karya, thik-ithik mamaoni, samubarang polah, tan kena wong kumlebat, ing mangsa mengko puniki, mapan wus lumrah, padha wasis maoni.

Mung tindake dhewe nora winaonan, ngrasa bener pribadi, sanadyan benera, yen tindake wong liya, pesthine ingaran sisip, iku kang lumrah, nganggo bener pribadi.

Nora nana panggawe kang luwih gampang, kaya wong mamaoni, sira lingelinga, aja sugih waonan, den samya raharjeng budi, ingkang prayoga, singa-singa kang lali. 
Pamoring Gusti kawula, pan iku ingkang sayekti, dadine sotya ludira, iku den waspada ugi, gampangane ta kaki, tembaga lawan mas iku, linebur ing dahana, luluh amor dadi siji, mari nama kencana miwah tembaga.

Puniku mapan upama, tepane badan puniki, lamun arsa ngawruhana, pamore kawula Gusti, sayekti kudu resik, aja katempelan nepsu, luwamah lan amarah, sarta suci lair batin, dadi mene sarira bisaa tunggal.

Terjemahannya

Apabila kau telah ditakdirkan menjadi orang terhormat, janganlah kau gila hormat, dan janganlah kau bergaul dengan orang jahat, sebab orang jahat itu akan mempengaruhimu.

Ada tiga hal kemurkaan, yang utama, yaitu tiga hal kemurkaan: jangan menyombongkan diri, dan jangan sampai, mengkritik dan mencela kekurangan orang lain.

Jangan sampai mencela pekerjaan orang lain, kendatipun hanya sedikit, segala sesuatunya tidak boleh ada yang mengungguli, zaman sekarang sudah lazim orang mengkritik.

Hanya perbuatannya sendiri tidak dicela, merasa benar sendiri, kendati benar, apabila orang lain, tentunya dikatakan salah, itu yang lazim, yang benar adalah dirinya sendiri.

Tidak ada perbuatan yang lebih mudah, seperti orang mencela, ingatingatlah, jangan terlalu mencela, lebih baik usahakan selalu menjaga keselamatan diri, jangan lupa.

Waspadalah: wujud bersatunya kawula-Gusti, bulat bagaikan butir darah. Hal itu sebagai lambang, dan itulah jalan yang harus ditempuh diri ini apabila ingin mengetahui wujud bersatunya kawula-gustinya; lahir dan batin harus bersih, janganlah ada napsu yang menempel, luamah dan amarah harus menyingkir, dengan demikian kawula akan dapat bersatu dengan Gustinya.

Berdasarkan kutipan dalam data tersebut, dapat disimpulkan bahwa SSDISKS Pakubuwana IV memberikan nasihat bahwa pemimpin harus selalu bersikap selalu waspada dan tidak gila hormat dalam situasi apapun terhadap siapapun juga dalam pergaulanserta agar selalu menjaga keselamatan diri. Pemimpin harus selalu waspada terhadap perbuatan rendah yang berasal dari hawa nafsu. Pemimpin harus selalu waspada terhadap kehidupan religiusnya (hubungan horisontal-vertikal) agar dapat mencapai manunggaling kawula-Gusti.

\section{Sabar}

Seorang pemimpin harus memiliki sifat sabar. Seseorang yang sabar akan memiliki keseimbangan emosi yang baik. Ia tidak akan mudah naik darah serta tidak mudah membuat keributan di sekitarnya. Seseorang yang suka membuat ribut dengan orang lain menandakan bahwa emosinya belum mantap sehingga hal itu menandakan bahwa ia tidak memiliki keseimbangan emosi. Orang yang 
demikian tidak bisa jadi pemimpin sebab seorang pemimpin harus mampumembuat suasana tenang dan senang. Maka seorang pemimpin harus mempunyaikeseimbangan emosi sehingga sikap sabar dapat diraihnya.

Dalam Serat Wedatama dijelaskan pula ajaran tentang sifat sabar yang harus dimiliki oleh seorang pemimpin. Pemimpin tidak boleh mudah marah dan harus selalu mengontrol keseimbangan emosinya dalam menghadapi setiap persoalan yang muncul. Berikut merupakan kutipan ajaran tentang sifat sabar yang tercantum dalam bait 16 pupuh Sinom.

"Samangsane pasamuwan, mamangun marta martani, sinambi ing saben mangsa ........." (Data II.16.c)

Terjemahannya

Dalam setiap pertemuan, menciptakan kebahagiaan lahir batin dengan sikap tenang dan sabar.

Seorang pemimpin yang mampu mengontrol keseimbangan emosinya maka ia dapat menularkan energi positif pada orang lain sehingga orang lain pun akan turut merasakan kebahagiaan dalam dirinya. Kesabaran selalu berkesinambungan dengan ketenangan hati dan jiwa yang dapat menuntun seorang pemimpin mampu menata emosi diri pribadinya sendiri.

Pada bait seterusnya dalam pupuh Sinom juga banyak dijelaskan tentang keharusan seorang pemimpin memiliki sifat sabar. Berikut merupakan bait-bait dalam Serat Wedatama yang menjelaskan tentang sifat sabar yang harus dimiliki oleh seorang pemimpin.

"Marang ingkang asung pangan, yen kasuwen den dukani, abubrah bawur tyas ingwang, lir kiyamat saben ari, ......" (Data II.27.c)

\section{Terjemahannya}

Oleh yang memberi makan, bila telat dimarahi, rusak dan bingung hatiku. Bagai kiamat setiap hari.

Pemimpin harus bersikap sabar dalam mengahadapi orang lain. Apapun yang terjadi ia harus sabar karena kesabarannya pasti akan membuahkan hasil suatu hari nanti. Pemimpin juga tidak boleh mudah marah jika bawahannya melakukan kesalahan sepele. Hal ini dikarenakan dapat merusak kepercayaan diri bawahannya untuk bisa melakukan hal-hal lain dengan lebih baik lagi karena hatinya akan terselimuti rasa takut terlebih dahulu.

"Beda lamun kang wus sengsem reh ngasamun, semune ngaksama, sasamane bangsa sisip, sarwa sareh saking mardi martatama" (Data III.35.e)

Terjemahannya

Lain halnya dengan yang sudah gemar kepada rohaniah. Nampak selalu mengampuni, segala kesalahan. Bersikap sabar karena berusaha berbudi baik. 
Pemimpin harus memiliki sifat sabar terhadap apapun kondisi yang sedang terjadi di sekitarnya, khususnya jika sedang memiliki banyak masalah. Seorang pemimpin yang sudah memiliki rohaniah yang baik, maka tentu saja ia memiliki hati yang lapang, sehingga ia akan lebih mudah bersikap sabar dalam menghadapi masalah yang ada.

"Durung pecus, kesusu kaselak besus, amaknani rapal, kaya sayid weton Mesir, pendhak pendhak angendhak gunaning janma." (Data III.38.b)

Terjemahannya

Belum pandai, tergesa-gesa ingin berlagak. Menerangkan rapal, seperti sayid dari Mesir. Seringkali meremehkan kepandaian orang lain.

Pemimpin harus bersikap sabar ketika akan melakukan sesuatu. Jangan tergesagesa dalam melakukan setiap hal, lebih baik dipikir secara matang-matang sebelum bertindak agar tidak salah keputusannya sehingga tidak akan merugikan orang lain.Dalam Serat Wedatama diterangkan bahwa seorang pemimpin jangan mudah merasa kecewa jika sedang kehilangan sesuatu atau sedang dilanda kesusahan. Ia harus sabar ketika menerima segala sesuatu yang menyakitkan hati dari orang lain. Berikut merupakan bait 43 pupuh Pocung yang menerangkan hal tersebut.

"Lila lamun, kelangan nora gegetun, trima yen ketaman, sakserik sameng dumadi, tri legawa nalangsa srah ing Bathara." (Data III.43.c, d)

Rela apabila kehilangan tidak masgul (kecewa), menerima (sabar) bila mendapat sesuatu yang menyakitkan hati dari orang lain. Tiga, ikhlas, menyerahkan kepada Tuhan.

Pemimpin harus memiliki kesabaran yang luas. Ia tidak boleh mudah marah apalagi sampai mencaci maki seenaknya sendiri. Jika orang lain melakukan kesalahan hendaknya ia ditegur dengan wajar tanpa harus mencaci makinya di depan orang banyak, lalu diberi tahu akan kesalahannya sehingga ke depan ia tidak mengulangi kembali kesalahannya. Kalaupun harus marah, maka seorang pemimpin sebaiknya marah dengan bijak sehingga kemarahannya itu benar-benar dapat menyadarkan orang lain yang melakukan kesalahan tersebut. Hal ini seperti yang tercantum dalam bait 45 pupuh Pocung sebagai berikut.

"Nora uwus, kareme anguwus uwus, uwose tan ana, mung janjine muring muring, kaya buta buteng betah nganiaya." (Data III.45. a-e)

Tidak henti-hentinya, kesukaannya mencaci maki. Tanpa isi, hanya asal marah-marah. Seperti raksasa mudah naik darah dan menganiaya.

Seorang pemimpin itu harus bersifat sabar, jangan mudah tergesa-gesa dalam menyelesaikan suatu perkara agar hasilnya memuaskan. Kesabaran dalam menyelesaikan suatu pekerjaan tentu akan menghasilkan hasil pekerjaan yang maksimal sehingga hasilnya dapat memberikan kepuasan tersendiri.

Seorang pemimpin harus mampu mengarahkan anak-anak buahnya agar memiliki kesabaran yang lebih dalam menyelesaikan setiap tugasnya, agar tujuan yang telah ditetapkan dapat tercapai dengan baik pula. Sifat tergesa-gesa itu merupakan suatu sikap yang tidak baik karena dapat menghancurkan segala sesuatu yang sebelumnya telah tertata dengan benar. Bahkan seorang pemimpin 
yang tergesa-gesa dalam menginginkan sesuatu justru dapat mengalami kekalahan akibat kesalahan yang diperbuatnya sendiri. Oleh karena itu, penting kiranya seorang pemimpin memiliki sikap sabar. Berikut merupakan ajaran kesabaran yang menerangkan hal tersebut yang tercantum dalam Serat Wedatama bait 52 pupuh Gambuh.

"Kasusu arsa weruh, cahyaning Hyang kinira yen karuh, ngarep arep uruba arsa den kurebi, tan wruh kang mangkono iku, akale kaliru enggon." (Data IV.52.a)

Tergesa-gesa ingin segera tahu, mengira kenal dengan cahaya Tuhan, mengharap cahaya akan ditelungkubi (dihormati), tidak tahu yang begitu itu, pandangannya tidak benar (salah tempat).

Untuk mencegah munculnya sikap tergesa-gesa maka perlu kiranya seorang pemimpin memiliki sikap sabar. Sikap sabar merupakan kunci terlaksananya segala sesuatu dengan optimal. Kesabaran sendiri dapat terlaksana jika orang tersebut memiliki ketenangan secara syahdu yang dijalankannya secara sadar pula. Sedikit demi sedikit, pelan namun pasti niscaya sikap sabar dapat ia miliki. Hal inilah yang diajarkan dalam Serat Wedatama bait 61 dan 67 pupuh Gambuh, seperti uraian berikut ini.

"Yen wus kambah kadyeku, sarat sareh saniskareng laku, kalakone saka eneng ening eling, ilanganing rasa tumlawung, kono adiling Hyang Manon." (Data IV.61.b)

Bila sudah mengalami seperti itu, saratnya sabar segala tindak tanduk. Terlaksananya dengan cara tenang syahdu tetapi tetap sadar. Bila rasa sayup sampai tadi hilang, itulah maha adilnya Tuhan.

"Pametake saka luyut, sarwa sareh saliring panganyut, lamun yitna kayitnan kang miyatani, tarlen mung pribadinipun, kang katon tinonton kono." (Data IV.67.b)

Sarannya dari luyut (batas lahir dan batin), serba sabar dalam mengikuti alam yang menghanyutkan. Asal waspada, dan kewaspadaan yang dapat diandalkan itu tak lain diri pribadinya yang terlihat disitu.

Seorang pemimpin juga harus memiliki kesabaran yang tinggi agar dapat menjalankan setiap petuah yang ia dapat. Kesabaran yang dimiliki nantinya dapat menghantarkan pada tercapainya kesentausaan dan keteguhan budi sehingga setiap petuah atau ilham yang ia terima dapat dilaksanakan dengan baik sehingga bisa bermanfaat bagi rakyat seluruhnya. Bait 73 pupuh Gambuh menerangkan hal tersebut dalam kutipan berikut ini.

"Pamoting ujar iku, kudu santosa ing budi teguh, sarta sabar tawekal legaweng ati, trima lila ambeg sadu, weruh wekasing dumados." (Data V.73.c)

Untuk melaksanakan petuah itu, harus sentausa dan teguh budinya. Dan sabar serta tawakal, ikhlas di hati, rela dan menerima segalanya, berjiwa pandita yang dapat dipercaya, paham akhir dari hidup ini.

Pemimpin harus memiliki kesabaran dalam melaksanakan setiap jenis kegiatan agar hasilnya memuaskan. Pemimpin tidak boleh mudah marah, ia harus bisa sabar dalam menghadapi segala masalah yang menghadang. Ia juga tidak boleh mudah melampiaskan hawa nafsunya kepada orang lain. Hal ini dikarenakan sikap 
sabar sangatlah dibutuhkan oleh seorang pemimpin untuk mendapatkan ilmu sejati tentang makna kehidupan. Seorang pemimpin yang mampu mengendalikan emosinya dengan sabar, niscaya akan meraih keberhasilan untuk mendapatkan ilmu hidup yang sejati. Dalam Serat Wedatama hal ini dijelaskan pada bait 94 pupuh Kinanthi sebagai berikut.

"Mangka ta kang aran laku, lakune ngelmu sajati, tan dahwen pati openan, tan panasten nora jail, tan njurungi ing kahardan, amung eneng mamrih ening." (Data VI.94.d)

Padahal yang disebut laku (sarat), saratnya menjalankan ilmu sejati, tidak iri dan dengki, tidak mudah marah dan jail, tidak melampiaskan hawa nafsu. Hanyalah diam agar dapat tenang (syahdu).

Dari berbagai macam wujud kesabaran di atas, maka dapat diambil kesimpulan bahwa seorang pemimpin haruslah memiliki kesabaran yang luas yang tercermin dalam setiap tindakannya yang senantiasa tabah dalam menghadapi setiap masalah yang terjadi, tidak mudah marah akan kesalahan orang lain, tidak tergesa-gesa dalam menyelesaikan setiap pekerjaan dan bentuk lain yang serupa sehingga semua tujuan yang ingin diraihnya dapat tercapai dengan maksimal. Tentu saja buah kesabaran akan berimbas pada orang-orang lain di sekitarnya yang akan membawa energi positif yang lebih besar pula.

Di samping itu, SSDISKS Pakubuwana IVmenuliskan dalam Serat Wulangreh bahwa pemimpin harus memiliki watak sabar. Kutipan mengenai watak sabar bagi seorang raja sebagaimana yang dimuat dalam IX.12.a-f sebagai berikut.

Den ajembar, den amot lan den amengku, den pindha segara, tyase ngemot ala becik, mapan ana papancene sowang-sowang.

Terjemahannya

Tanggapan kita haruslah luas dan dalam bagaikan samodra. Mereka harus dapat menerima adanya baik dan buruk sikap setiap orang.

Berdasarkan kutipan dalam data di atas, dapat disimpulkan bahwa SSDISKS Pakubuwana IV memberikan nasihat bahwa seorang pemimpin harus selalumemiliki watak sabar, yakni menerima segala sesuatu kejadian yang dialami yang berasal dari berbagai kalangan, baik yang berhubungan dengan sikap baik dan buruk maupun yang berhubungan dengan masalah ringan dan berat. Hal itu harus ditanggapi dan diselesaikan secara sabar, tenang, dan berani bertanggung jawab.

\section{Taat Beragama}

Berdasarkan yang tertulis dalamKamus Besar Bahasa Indonesia, kata agama merupakan suatu sistem yang mengatur tata keimanan dan peribadatan kepada Tuhan Yang Mahakuasa serta tata kaidah yang berhubungan dengan pergaulan manusia dengan manusia serta lngkungannya. Kata agama berasal dari bahasa Sansekerta, yakni dari akar kata gam mendapat imbuhan prefiks $\bar{a}$. Jadi, kataāgama berarti tradisi. Kata lain untuk menyatakan konsep ini adalah religi, yang berasal dari bahasa Latin religio yang berarti mengikat kembali. Maksudnya dengan beriligi, seseorang mengikat kepada Tuhan. Seseorang yang menjalankan 
ibadahnya dengan tekun dan benar disebut orang yang taat beragama (Kamaluddin, 2016: 77).

Seorang pemimpin haruslah menjadi pengikut agama yang baik, karena agama merupakan pedoman hidup yang baik. Seperti yang dikemukakan KGPH Mangkunegara IV, di dalam Serat Wedhatama bahwa pemimpin harus seorang yang taat beragama, sebagaimana tertulis dalam kutipan dari teks data I.1.g; II.26.i; II.28.e; IV.65.d-e; IV.72.c; dan V. 74. sebagai berikut.

Sinuba sinukarta, mrih kretarta pakartining ngelmu luhung,kangtumrap ing tanah Jawa, agama ageming aji.

Sawadine tyas mami, banget wedine ing mbesuk, pranatan ngakir jaman, tan tutug kaselak ngabdi, nora kober sembahyang gya tinimbalan.

Angur baya ngantepana, pranatan wajibing urip, lampahan angluluri, kuna kumunanira, kongsi tumekeng samangkin, kikisane tan lyan amung ngupa boga.

Ruktine ngangkah ngukut, ngiket ngruket triloka kakukut, jaga agung ginulung lan jaga alit, den kandel kumandel kulup, mring kelaping alam kono.

Meloke ujar iku, yen wus ilang sumelanging kalbu, amung kandel kumandel marang ing takdir, iku den awas den emut, den memet yen arsa momot.

Sabarang tindak tanduk, tumindake lan sakadaripun, den ngaksama kasisipaning sesami, sumimpanga ing laku dur, hardaning budi kang ngrodon.

Terjemahannya

Dihias penuh variasi, biar menjiwai ilmu luhur yang dituju, Di tanah Jawa (Indonesia) ini yang hakiki itu adalah agama sebagai pegangan yang baik.

Sesungguhnya relung hati saya, sangat takut akan hari esok, menghadapi akhir hayat. Belum selesai berguru, terhenti karena harus mengabdi. Tidak sempat sembahyang lalu dipanggil menghadap.

Lebih baik berpegang teguh, tata peraturan kehidupan. Menjalankan serta mengikuti jejak para leluhur, di zaman dahulu kala hingga masa kini. Akhirnya tidak lain hanyalah mencari nafkah.

Memeliharanya (caranya dengan) berusaha menguasai, mengikat, merangkul tiga jaga dikuasai. Jagad besar digulung dengan jagad kecil. Perkuatlah kepercayaanmu anakku, terhadap keadaan/ gemerlapannya alam itu. 
Kenyataan yang dibicarakan ini. Bila sudah hilang keragu-raguan hati, hanya percaya dengan sebenar-benarnya kepada takdir. Itu harap awas dan ingat. Yang cermat apabila ingin menguasai seluruhnya.

Segala tindak tanduk, dikerjakan sekadarnya, memberi maaf terhadap kesalahan sesama, menghindari dari tindakan tercela, watak angkara yang besar.

Berdasarkan kutipan dalam data tersebut, dapat disimpulkan bahwa KGPH Mangkunegara IV memberikan nasihat yang menyiratkan bahwa pemimpin harus menjadi percaya pada Tuhan, rajin beribadah, pikirannya hanya tertuju pada Sang Khaliq, hatinya senantiasa ingat akan Tuhan dan hari akhir sehingga segala perilakunya akan selalu berpedoman pada ajaran agama yang dianutnya. Pemimpin haruslah orang yang taat beragama tercermin dari setiap tindakannya yang hanya berusaha menjalankan perbuatan yang baik dan menghindari tindakan yang tercela.

SSDISKS Pakubuwana IV sebagai pengikut agama yang baik atau taat beragama juga terdapat di dalam Serat Wulangreh. Hal tersebut terdapat pada kutipan teks data I.6.a-j, IV.8.a-g, VI.17.a-e, XI.1.2.a-g, dan XI.3.4.a-g sebagai berikut.

Ana uga kena denantepi, yen ucul saka patang prakara, nora enak legetane, tan wurung tinggal wektu, panganggepe wus angengkoki, aja kudu sembahyang, wus salat katengsun, banjure mbuwang sarengat, batal karam nora nganggo denrawati, bubrah sakehing tata.

Ginulang sadina-dina, wiwekane mindeng basa basuki, ujubriya kibiripun, sumungah tan kanggonan, mung sumendhe ing karsanira Hyang Agung, ujar sirik kang rineksa, kautaman ulah-wadi.

Tulisane ing lokil-makful rumuhun, papancen sawiji-wiji, tan kena owah sarambut, tulising badan puniki, aja na mundur pakewoh.

Padha netepana ugi, kabeh parentahing sarak, terusna lair batine, salat limang wektu uga, tan kena tininggala, sapa tinggal dadi gabug, yen misih dhemen neng praja.

Wiwit ana badan iki, iya teka ing sarengat, ananing manungsa kiye, rukun Islam kang lilima, nora kena tininggal, iku parabot linuhung, mungguh wong urip neng dunya.

Kudu uga den lakoni, rukun lelima punika, mapan ta sakuwasane, nanging aja tan linakyan, sapa tan nglakonana, tan wurung nemu bebendu, padha sira estokena.

Parentahira Hyang Widdhi, kang dhawuh mring Nabiyullah, ing dalil kadis enggone, aja na ingkang sembrana, rasakna den karasa, dalil kadis rasanipun, dadi padhang ing tyasira. 
Terjemahannya

Hal itu haruslah kau pertimbangkan dan kau pikirkan terlebih dahulu, setidak-tidaknya salah satu dari yang dikatakannya haruslah sesuai dengan empat hal tersebut di atas. Apabila hal itu menyimpang dari empat hal yang diperkatakan di atas, hal itu tidak dapat dijadikan pegangan, akhirnya apa yang diperkatakannya akan menyimpang dari syari'at (hukum agama Islam yang diamalkan menjadi perbuatan-perbuatan); batal dan haram tidak kau ketahui, merusak peraturan (tata tertib).

Setiap hari berusaha mempelajari rintangan menuju hidup selamat, menjaga jangan sampai menyombong-kan diri, merasa diri kaya, hanya berserah diri pada kehendak Tuhan, menjauhkan diri perbuatan sirik, selalu menjaga perbuatan utama.

Untung dan rugi, terhormat dan terhina, itu sudah ditentukan (ditakdirkan) oleh Tuhan. Kepastiannya dapat diumpamakan 'tidak boleh berubah sedikitpun'. Hal itu sudah tertulis dalam lochil machfoel(buku yang memuat takdir manusia).

Orang hidup di dunia, haruslah menjalankan peraturan agama secara lahir batin. Menjalankan salat lima waktu, tidak boleh ditinggalkan, siapa meninggalkan menjadi orang yang tidak patut. Asal mula manusia dalah dari syariat, rukun Islam terdiri atas lima hal, tidak boleh ditinggalkan. Hal itu adalah pedoman hidup manusia di dunia.

Barang siapa yang tidak menjalani rukun Islam dia akan mendapat bala, perhatikanlah dengan baik. Patuhlah pada sabda Tuhan melalui nabi Muhammad, sebagaimana disebut dalam dalil dan hadist, sehingga menjadikan hati tenang.

Berdasarkan kutipan dalam data tersebut, dapat disimpulkan bahwa SSDISKS Pakubuwana IV memberikan nasihat yang menyiratkan bahwa pemimpin harus senantiasa mempertimbangkan dan membedakan, segala sesuatu yang dilakukan berdasarkan peraturan agama dan menjauhi segala sesuatu yang menyimpang. Seorang pemimpin harus setiap hari senantiasa berusaha agar hidupnya selamat dengan menghindari diri dari perbuatan buruk dan selalu berserah diri kepada kehendak Tuhan. Juga, harus percaya adanya takdir, harus patuh dan tertib melaksanakan peraturan agama, dan harus patuh dan tertib melaksanakan peraturan agama.

\section{Prihatin}

Prihatin dari kata dasar prihatin artinya sedih hati yang mendalam karena usahanya gagal, mendapat kesulitan, mengingat akan nasibnya, dll. Berprihatin adalah melakukan tindakan yang membuat dirinya menjadi dapat merasakan bagaimana ketika sedang sedih hati. Berprihatin, dalam hal ini, tindakan untuk 
menempa jiwa dan raga agar mendapatkan kekuatan, baik lahir/jasmani maupun batin/rohani untuk menghadapi dan menghilangkan kesedihan bagi dirinya sendiri, dan juga orang lain. Selain itu, juga dapat ikut merasakan kesedihan orang lain. Dengan ikut merasakan kesedihan orang lain, maka otak dan hati akan terdorong untuk mencari solusinya. Dengan demikian, berbagai kesediah yang dirasakan oleh orang lain akan teratasi dan terpecahkan kesulitannya.

SSDISKS Pakubuwana IVmenuliskan dalam Serat Wulangreh bahwa pemimpin harus mau berprihatin. Kutipan mengenai berlaku prihatin bagi seorang raja sebagaimana yang dimuat dalam teks data pada pupuh Kinanthi bait 2 baris 1 6; pupuh Durma bait 1 baris 1-7; pupuh Sinom bait 6, 10 baris 1-8; pupuh Girisa bait 23 baris $1-8$ sebagai berikut.

Dadia lakunireku, cegah dhahar lawan guling, lan aja sukan-sukan, anganggoa sawatawis, ala watake wong suka, nyuda prayitnaning batin. (Data II.2.a-f)

Dipunsami ambanting sariranira, cegah dhahar lan guling, darapon sudaa, nepsu kang ngambra-ambra, rerema ing tyasireki, dadi sabarang, karsanira lestari. (Data VII.1.a-g)

Lan aja na lali padha, mring luluhur ingkang dingin, satindake denkawruhan, angurangi dhahar guling, nggone ambanting dhiri, amasuh sariranipun, temune kang sineja, mungguh wong nedha ing Widdhi, lamun temen lawas enggale tumekan. (Data XII.6.a-i)

Ana ta silih bebasan, padha sinaua ugi, lara sajroning kapenak, suka sajroning prihatin, lawan ingkang prihatin, mapan suka ing jronipun, iku densinaua, lan mati sajroning urip, ing wong kuna pan mangkono kang den gulang. (Data XII.10.a-i)

Lan mugi padha tirua, kaya leluhure padha, sudira betah atapa, sarta waskitha ing nala, ing kasampurnaning gesang, kang patitis nora mamang, iku ta panedhaningwang, muga padha kalakona. (Data XIII.23.a-h)

Terjemahannya

Perihal mengurangi makan dan tidur itu jadikanlah peri laku sehari-hari. Janganlah kau terlalu banyak berfoya-foya. Pakailah ukuran kalau berfoyafoya, sebab sifat orang yang suka berfoya-foya itu akan membawa orang pada ketaksadaran diri.

Tirakatlah, jangan terlalu banyak makan dan terlalu banyak tidur agar supaya nafsu yang menyala-nyala berkurang dan hati dapan tenang tenteram. Akhirnya segala sesuatu yang diharapkan tentu akan terlaksana.

Janganlah melupakan kehidupan nenek moyang. Ketahuilah dan pahamilah jalan hidupnya, yaitu dengan mengurangi makan minum, 
bekerja keras, mematangkan diri untuk mencapai keinginan dengan selalu memohon kepada Tuhan semoga lekas tercapai.

Ada ibarat yang baik untuk dipahami: "belajarlah menderita dalam saat bahagia, gembira dalam saat prihatin, prihatin dalam saat gembira, dan mati dalam saat hidup',

Menirulah perjalan hidup nenek moyang dengan selalu berprihatin (bertapa) agar selalu waspada, dan sempurna dalam hidupnya, selalu berhati-hati, jangan ragu-ragu.

Berdasarkan kutipan dalam data tersebut, dapat disimpulkan bahwa SSDISKS Pakubuwana IV memberikan nasihat bahwa seorang pemimpin harus mau berprihatin,dengan cara tidak mengutamakan makan dan tidur, tidak berfoyafoya dan selalu terjaga terjaga dari ketaksadaran diri. Seorang pemimpin harus mau berprihatin dengan cara tirakat dan mengekang hawa nafsu, bekerja keras, mematangkan diri,serta senantiasa memohon untuk mencapai keinginan. Di samping itu, juga dapat memahami istilah: "belajarlah menderita dalam saat bahagia, gembira dalam saat prihatin, prihatin dalam saat gembira, dan mati dalam saat hidup'. Dengan demikian, kewaspadaan dan "kesempurnaan" hidup seluruh rakyatnya akan tetap terjaga.

\section{PENUTUP}

Berdasarkan studi awal dalam penelitian ini, terdapat banyak sekali manuskrip-manuskrip Jawa yang memuat mengenai sifat-sifat kepemimpinan. Namun pada penelitian ini baru dapat dibahas dua buah naskah Jawa yang memuat kepemimpinan. Oleh karena itu, perlu penelitian lebih lanjut mengenai leadhership characters dalam naskah-naskah Jawa yang lain seperti Serat Bustam, Serat Nitipraja, Serat Pustaka Raja, dan lain-lain mengingat leadership characters dalam dua serat yang diteliti juga masih relevan dengan kondisi masyarakat modern.

\section{DAFTAR PUSTAKA}

Anjar Any. Menyingkap Serat Wedotomo. Semarang: Aneka Ilmu.

Baroroh-Baried, Siti dk.k. 1994. Pengantar Teori Filologi. Yogyakarta: Badan Penelitian dan Publikasi Fakultas (BPPF) Seksi Filologi, Fakultas Sastra Universitas Gadjah Mada.

Behrend, T.E. dkk. 1990. Katalog Induk Naskah-naskah Nusantara: Museum Sonobudoyo Yogyakarta. Jilid I. Jakarta: Djambatan.

Darmoko, 2012. Nilai-nilai Kepemimpinan Jawa Untuk Membangun Kehidupan Bangsa. dalam Jurnal IKADBUDI Jurnal Ilmiah Bahasa, Sastra, Dan Budaya Daerah.Yogyakarta: Ikatan Dosen Budaya Daerah Se-Indonesia bekerja sama dengan Jurdik Bahasa Daerah FBS UNY.

Kamaluddin.7 Kesalahan Fatal Suami. Yogyakarta:Pustaka Ilmu Semesta.

KGPAA Mangkunegara IV, http://www.mangkunegara4.org/index.php/tentang mn-iv diunduh: Kamis, 25 Februari 2016, 06.45. 
Kuntowijoyo. 2006. Raja, Priyayi, dan Kawula. Yogyakarta: Ombak.

Loir, H.C. dan Fathurahman, O. 1999. Khazanah Naskah: Panduan Koleksi Naskah Indonesia se-Dunia (Manuscript Treasures: World Guide to the Indonesian Collection Jakarta: Yayasan Obor Indonesia dan Ecole Francaise d' Extreme Orient.

Mulyani, Hesti. 2014a. Unsur Kebudayaan Jawa dalam Teks Pamoripun Saréngat, Tarékat, Kakékat, lan Makrifat. Jurnal Ikadbudi. Volume 3, Oktober 2014. Yogyakarta: Ikatan Dosen Budaya Daerah Se-Indonesia Bekerjasama dengan Jurusan Pendidikan Bahasa Daerah Fakultas Bahasa dan Seni Universitas Negeri Yogyakarta.

Mulyani, Hesti. 2014b. Teori dan Metode Pengkajian Filologi. Yogyakarta: Astungkāra Media.

Mulyani, Hesti. 2014c. Pendidikan Karakter dalam Abjad Jawa (Suatu Tinjauan terhadap Serat Mursida Jati. Memantapkan Pendidikan Karakter untuk Melahirkan Insan Bermoral, Humanis, dan Profesional. Pemikiran Civitas Akademika Universitas Negeri Yogyakarta dalam Rangka Dies Natalis ke50. Yogyakarta: UNY Press.

Nurhayati, Endang, dkk. 2011. Mencari Benang Merah Pemikiran Melayu-Jawa Melalui Pengajian Manuskrip Kuna. Yogyakarta: Laporan Penelitian FBS UNY.

Nurhayati, Endang.2006. Ajaran Hidup dan Falsafah dalam Naskah Jatipusaka Makutharaja Relevansinya dengan Kehidupan Dewasa Ini.dalam Filsafat dan Ajaran Hidup dalam Khasanah Budaya Keraton Yogyakarta. Yogyakarta: Yayasan Kebudayaan Islam Indonesia bekerja sama dengan UIN Sunan Kalijaga Yogyakarta.

Pigeaud, T.G.T. 1967. Literature of Java Vol. I: Synopsis of Javanese Literature. Leiden: The Hague Martinus Nyhoff.

Pradipta, Budya. 1998. Pengaruh Ramayana ke dalam Filsafat Hidup Jawa dan Tantangannya. Ramayana: Transformasi, Pengembangan dan Masa Depannya. Buku kumpulan Makalah dalam Seminar. Halaman: 166-187. Yogyakarta: Lembaga Studi Jawa Bekerjasama dengan Program Studi Pendidikan Bahasa Jawa FPBS IKIP Yogyakarta.

Saktimulya, Sri Ratna. 2005. Katalog Naskah-Naskah Perpustakaan Pura Pakualaman. Jakarta: Yayasan Obor Indonesia.

Salahudin, Anas dan Irwanto Alkrienciehie. 2013. Pendidikan Karakter: Pendidikan Berbasis Agama \& Budaya Bangsa. Bandung: Pustaka Setia.

Sri Susuhunan Pakubuwana IV. Serat Wulangreh. tt.

Sunyoto, Agus. 2012. Atlas Wali Songo.Jakarta: Pustaka IlMan bekerja sama dengan Trans Pustaka dan LTN PBNU.

Supariadi. 2001. Kyai dan Priyayi di Masa Transisi. Surakarta: Yayasan Pustaka Cakra. 